and outcomes of extravesical and intravesical approaches. Eur Urol 2013;64:831-836.

4. Lee RS, Sethi AS, Passerotti CC, et al. Robot assisted laparoscopic partial nephrectomy: A viable and safe option in children. J Urol 2009;181:823-829.

5. Marchini GS, Hong YK, Minnillo BJ, et al. Robotic assisted laparoscopic ureteral reimplantation in children: Case matched comparative study with open surgical approach. J Urol 2011;185:1870-1875.

6. Pelizzo G, Nakib G, Goruppi I, et al. Pediatric robotic pyeloplasty in patients weighing less than $10 \mathrm{~kg}$ initial experience. Surg Laparosc Endosc Percutan Tech 2014;24: e29-e31.

7. Wille MA, Jayram G, Gundeti MS. Feasibility and early outcomes of robotic-assisted laparoscopic Mitrofanoff appendicovesicostomy in patients with prune belly syndrome. BJU Int 2012;109:125-129.

8. Johnson KC, Cha DY, DaJusta DG, et al. Pediatric singleport-access nephrectomy for a multicystic, dysplastic kidney. J Pediatr Urol 2009;5:402-404.

9. Varda BK, Johnson EK, Clark C, et al. National trends of perioperative outcomes and costs for open, laparoscopic and robotic pediatric pyeloplasty. J Urol 2014;191:10901095.

10. Lee RS, Retik AB, Borer JG, Peters CA. Pediatric robot assisted laparoscopic dismembered pyeloplasty: Comparison with a cohort of open surgery. J Urol 2006;175:683687.

11. Dangle PP, Kearns J, Anderson B, Gundeti MS. Outcomes of infants undergoing robot-assisted laparoscopic pyeloplasty compared to open repair. J Urol 2013;190:22212226.
12. Lindgren BW, Hagerty J, Meyer T, Cheng EY. Robotassisted laparoscopic reoperative repair for failed pyeloplasty in children: A safe and highly effective treatment option. J Urol 2012;188:932-937.

13. Mitrofanoff P. [Trans-appendicular continent cystostomy in the management of the neurogenic bladder]. (Fre) Chir Pediatr 1980;21:297-305.

14. Harris CF, Cooper CS, Hutcheson JC, Snyder HM 3rd. Appendicovesicostomy: The mitrofanoff procedure - a 15year perspective. J Urol 2000;163:1922-1926.

15. Nguyen HT, Passerotti CC, Penna FJ, et al. Robotic assisted laparoscopic Mitrofanoff appendicovesicostomy: Preliminary experience in a pediatric population. J Urol 2009; 182:1528-1534.

16. Wille MA, Zagaja GP, Shalhav AL, Gundeti MS. Continence outcomes in patients undergoing robotic assisted laparoscopic mitrofanoff appendicovesicostomy. J Urol 2011;185:1438-1443.

Address correspondence to:

Patricio C. Gargollo, MD

Texas Children's Hospital

Baylor College of Medicine

6701 Fannin Street, 8th Floor

Houston, TX 77030

E-mail: pcgargol@texaschildrens.org

Abbreviation Used

$\mathrm{APV}=$ appendicovesicostomy

DOI: 10.1089/end.2014.0723

\title{
Editorial Comment for Chung et al.
}

\author{
Mohan Gundeti, MD
}

$\mathbf{I}_{\mathrm{r}}^{\mathrm{N}}$ $\mathrm{N}$ THE REALM of continually growing pediatric robotic urologic surgery, this is the next milestone in regard to its applications for redo reconstructive surgery. The at par outcomes in complex lower urinary tract reconstruction ${ }^{1}$ have allowed the surgeons with experience to achieve this next step. Of utmost importance is to know that these procedures necessitate a certain level of expertise and need to be exercised at well-established centers.

The important point to note about the added advantage, here demonstrated by the authors, is the reduced intraperi- toneal adhesions that we have previously seen in the porcine model, ${ }^{2}$ which may be an additional benefit for the spina bifida population to further reduce abdominal complications with multiple surgeries (e.g., intestinal obstruction) with this approach.

The question that remains is how can we convince the readers about reduced morbidity and sustainable results? Hence, the next goal in this field should be to conduct a comparative study with prospective long-term follow-up. It is also crucial to develop a robust training program for these complex reconstructions ${ }^{3}$ and create

Department of Surgery (Urology), University of Chicago, Chicago, Illinois 
an algorithm to prevent complications, especially stomal incontinence. ${ }^{4}$

\section{References}

1. Famakinwa OJ, Rosen AM, Gundeti MS. Robot-assisted laparoscopic Mitrofanoff appendicovesicostomy technique and outcomes of extravesical and intravesical approaches. Eur Urol 2013;64:831-836.

2. Razmaria AA, Marchetti PE, Prasad SM, et al. Does robotassisted laparoscopic ileocystoplasty (RALI) reduce peritoneal adhesion compared with open surgery? BJU Int 2014; 113:468-475.
3. Kearns JT, Gundeti MS. Pediatric robotic urologic surgery2014. J Indian Assoc Pediatr Surg 2014;19:123-128.

4. Wille MA, Zagaja GP, Shalhav AL, Gundeti MS. Continence outcomes in patients undergoing robotic assisted laparoscopic mitrofanoff appendicovesicostomy. J Urol 2011; 185:1438-1443.

Address correspondence to: Mohan Gundeti, MD Department of Surgery (Urology) University of Chicago 5841 S. Maryland Avenue Chicago, IL 60637

E-mail: mgundeti@surgery.bsd.uchicago.edu 